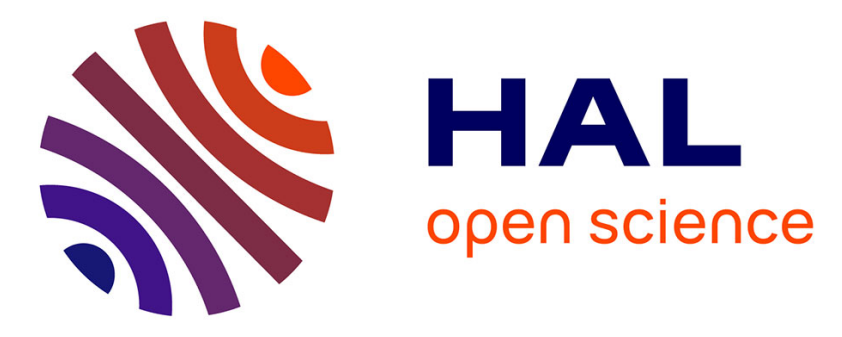

\title{
Fatal acetaminophen poisoning with hepatic microvesicular steatosis in a child after repeated administration of therapeutic doses
}

Renaud Bouvet, Aurelie Cauchois, Alain Baert, Bernard Fromenty, Isabelle Morel, Bruno Turlin, Thomas Gicquel

\section{To cite this version:}

Renaud Bouvet, Aurelie Cauchois, Alain Baert, Bernard Fromenty, Isabelle Morel, et al.. Fatal acetaminophen poisoning with hepatic microvesicular steatosis in a child after repeated administration of therapeutic doses. Forensic Science International, 2020, 310, pp.110258. 10.1016/j.forsciint.2020.110258 . hal-02563468

HAL Id: hal-02563468

https://hal-univ-rennes1.archives-ouvertes.fr/hal-02563468

Submitted on 14 May 2020

HAL is a multi-disciplinary open access archive for the deposit and dissemination of scientific research documents, whether they are published or not. The documents may come from teaching and research institutions in France or abroad, or from public or private research centers.
L'archive ouverte pluridisciplinaire HAL, est destinée au dépôt et à la diffusion de documents scientifiques de niveau recherche, publiés ou non, émanant des établissements d'enseignement et de recherche français ou étrangers, des laboratoires publics ou privés. 
Fatal acetaminophen poisoning with hepatic microvesicular steatosis in a child after repeated administration of therapeutic doses

Renaud Bouvet ${ }^{1,2}$, Aurélie Cauchois ${ }^{1,5}$, Alain Baert ${ }^{1}$, Bernard Fromenty ${ }^{3}$, Isabelle Morel ${ }^{3,4}$, Bruno Turlin ${ }^{3,5}$, Thomas Gicquel ${ }^{3,4}$

${ }^{1}$ Department of Forensic Medicine, Rennes University Hospital, Rennes, France. ${ }^{2}$ IDPSP EA 4640, Rennes University, Rennes, France. ${ }^{3}$ Univ Rennes, Inra, Inserm, Institut NUMECAN - UMR_A 1341, UMR_S 1241, Rennes, France. ${ }^{4}$ Department of Forensic Toxicology, Rennes University Hospital, Rennes, France. ${ }^{5}$ Department of Pathology, Rennes University Hospital, Rennes, France

Corresponding author at: Rennes University Hospital. Department of Forensic Toxicology 2, rue Henri Le Guilloux 35033 Rennes cedex 9, France E-mail address : thomas.gicquel@ chu-rennes.fr (T. Gicquel)

\begin{abstract}
Acetaminophen is the leading cause of acute liver failure worldwide following massive ingestion. We present here a fatal acute liver failure after repeated administration of four therapeutic doses of acetaminophen at 4-hour intervals in a previously healthy 9-year-old female who presented dental pain after a facial trauma during sport practice. A diagnosis of paracetamol-induced hepatitis was deduced from the clinical picture of fulminant hepatitis and tubular necrosis, the encephalopathy with oedema and without signs of trauma. Liver biopsy showed typical acetaminophen-induced necrosis and a microvesicular steatosis in periportal hepatocytes. These injuries might have been favored by pre-existing mitochondrial
\end{abstract}


dysfunction related, for instance, to a deficiency in an enzyme of the mitochondrial $\beta$ oxidation pathway, or the respiratory chain. The observation of microvesicular steatosis in the periportal areas suggests an increased vulnerability via pre-existing mitochondrial dysfunction. As the liver status of patients is mostly unknown, the frequency of administration (every six hours) must be respected and the use of pharmaceutical forms allowing to adjust the dose as closely as possible to the child's weight should be promoted.

Key words : Acetaminophen-induced hepatotoxicity, Pediatric acute-liver, failureMicrovesicular steatosis, Painkiller toxicity, Death

\begin{abstract}
Abbreviations
ALF : acute liver failure, CT: Computed Tomography, CYP: cytochrome P450, NAPQI: Nacetyl-p-benzoquinoneimine
\end{abstract}

\title{
1. Introduction
}

Acetaminophen is the leading cause of acute liver failure (ALF) worldwide, either following intentional overdose or unintentional ingestion [1]. The number of deaths in North America and Europe shows no sign of decreasing, despite some efforts to limit package size in the United Kingdom and the availability of an antidote [2]. Few cases of acetaminophen-induced ALF with slightly supratherapeutic doses have been reported in children [3, 4]. We present a fatal acute liver failure after repeated administration of four therapeutic doses of acetaminophen at 4-hour intervals in a previously healthy 9-year-old female. Liver biopsy 
showed typical acetaminophen-induced necrosis and a microvesicular steatosis in periportal hepatocytes. This case highlights that as the liver status of patients is mostly unknown, the frequency of administration must be respected and the use of pharmaceutical forms allowing to adjust the dose as closely as possible to the child's weight should be promoted.

\section{Case report}

We report the case of a girl aged 9 years with unremarkable medical history (weight $30 \mathrm{~kg}$; height: $1.35 \mathrm{~m}$; body mass index $16.5 \mathrm{~kg} / \mathrm{m}^{2}$ ). She developed dental pain after a facial trauma during sport practice. Her mother gave her a tablet of acetaminophen (acetaminophen) $500 \mathrm{mg}$ on four occasions, with a 4-hour interval between each dose. In the evening, the girl experienced abdominal pain with vomiting. At 48 hours after taking acetaminophen, vomiting was still present, and headaches and confusion developed.

The clinical examination in the paediatric emergency department showed somnolence. Laboratory testing showed hepatocellular insufficiency (prothrombin ratio: 12\%; factor V: 12\%), cytolysis (AST: $11500 \mathrm{IU} / \mathrm{L}$; ALT: $16200 \mathrm{IU} / \mathrm{L}$ ), lactate: $5 \mathrm{mmol} / \mathrm{L}$. and renal insufficiency (urea: $18 \mathrm{mmol} / \mathrm{L}$; creatinine: $120 \mu \mathrm{mol} / \mathrm{L}$ ). The acetaminophen blood concentration was measured at $8.9 \mu \mathrm{g} / \mathrm{mL}$. Treatment with intravenous $\mathrm{N}$-acetylcysteine (3g/24h) was initiated according to usual habits and the girl was admitted to the paediatric intensive care unit. Intracranial hypertension was treated with boluses of thiopental sodium, mannitol and moderate hyperventilation. A cranial CT scan demonstrated diffuse cerebral oedema with involvement of the cerebellum, without any haemorrhagic lesion. There was also a mild focal infection around one of the upper right molars. Laboratory results clearly demonstrated severe hepatocellular insufficiency (prothrombin ratio: 11\% 12 hours after 
admission in the paediatric emergency department then $<10 \% 3$ hours later, justifying infusion of fibrinogen; at the time of the death, prothrombin ratio: $21 \%$ ), and also functional renal insufficiency, with diuresis preserved. A haemodynamic failure necessitated the infusion of normal saline solution and noradrenaline, then, following development of cardiac insufficiency (ejection fraction $<20 \%$ ), dobutamine. In the presence of terminal liver failure with hepatorenal syndrome, high-volume haemodiafiltration $(60 \mathrm{ml} / \mathrm{kg})$ was started. A liver biopsy was performed to investigate this liver failure. Despite the initial regression of mydriasis, the neurological picture evolved to brain death. An autopsy was performed at the request of the judicial authority.

Additional investigations did not find any markers in support of a viral infection (hepatitis A, B, C, E; HIV; EBV; HSV; VZV) or autoimmune hepatitis (negative for presence of antismooth muscle antibodies, anti-mitochondrial antibodies, anti-LKM1 antibodies, anti-LC1 antibodies and anti-parietal cell antibodies). Testing for amanitin in urine was negative. Ceruloplasmin and urine and plasma copper concentrations, and the absence of copper deposits on liver biopsy allowed Wilson disease to be ruled out.

The liver biopsy showed two features. The first was necrosis in the centri and mediolobular zones, affecting $60 \%$ of hepatocytes (Figure 1A). This feature was typical of acetaminopheninduced necrosis. The second feature was microvesicular steatosis in periportal hepatocytes (Figure 1B). There were no fibrosis or inflammation. Perls staining did not find any evidence of haemosiderin deposition. Examination of a renal parenchymal specimen obtained during the autopsy showed several areas of eosinophilic necrosis of approximately $70 \%$ of tubules, with total disappearance of nuclei. Glomeruli were on the whole preserved, although there were some eosinophilic deposits in the form of crescents. The neuropathological examination 
revealed multifocal subdural and subarachnoid haemorrhage with interstitial oedema and massive neuronal loss. There were no signs of infection.

A diagnosis of acetaminophen-induced hepatitis was deduced from the clinical picture of fulminant hepatitis and tubular necrosis, the encephalopathy with oedema and without signs of trauma, and the results of additional investigations, especially necrosis of hepatocytes with eosinophilic and apoptotic aspect, without inflammation. A thorough police investigation confirmed that four tablets of acetaminophen $500 \mathrm{mg}$ had indeed been administered at 4-hour intervals and that no other treatment had been used. Figure 2 provides the time frame of events of this case according to police investigation and patient medical records.

\section{Discussion}

The pain reliever acetaminophen is one of the most widely prescribed drugs in the world. Although this medicine is usually considered as a safe drug, there is inscreasing evidence that the current maximum recommended dose of acetaminophen can induce hepatic cytolysis in a significant proportion of healthy subjects $[5,6]$.

In the absence of comorbidity, acetaminophen is prescribed at a dose of $15 \mathrm{mg} / \mathrm{kg}$ every 6 hours (60 mg/kg per day) for children weighing more than $10 \mathrm{~kg}$, and $7.5 \mathrm{mg} / \mathrm{kg}$ every 6 hours (30 mg/kg per day) for children weighing less than $10 \mathrm{~kg}$. The dosage of $150 \mathrm{mg} / \mathrm{kg}$ per day or as a single dose is widely accepted as the toxicity threshold. Nevertheless, Kozer et al. [7] and Heard et al. [8] proposed that the dose of $75 \mathrm{mg} / \mathrm{kg}$ per day could be considered without risk in children aged less than six years. More recently, Caparrotta et al. [9] estimated that the 
safe (and still effective) oral dose of acetaminophen in patients weighing less than $50 \mathrm{~kg}$ had not been established.

In our case, the results of investigations allowed to conclude that the death was caused by acetaminophen poisoning: the diagnostic work-up allowed to eliminate differential diagnoses and to rule out an intercurrent pathological process and exposure to other medications, in contrast to other publications $[10,11]$. This conclusion must be discussed with the following reservations: the speed of onset of fatal hepatitis does not correspond to the usually observed evolution, the evaluation of the ingested dose was based on the statements of the family, the absence of urine samples does not allow to assess the exposure to xenobiotics based on a full toxicological analysis. The pharmacogenetic study of cytochrome P4502E1 (CYP2E1) was not carried out [12], as well as the study of possible interference associated with other drug or dietary xenobiotics. However, these reservations would not affect the finding of acetaminophen exposure as the probable cause of death. Acetaminophen was administered at a dose of $16.7 \mathrm{mg} / \mathrm{kg}$ every four hours for twelve hours, giving a cumulative dose of 66.6 $\mathrm{mg} / \mathrm{kg}$ in twelve hours, which is lower than the dose of $75 \mathrm{mg} / \mathrm{kg}$ per day considered safe in children aged below six years, and much lower than the commonly accepted toxicity threshold of $150 \mathrm{mg} / \mathrm{kg}$ per day.

Unintentional administration of supratherapeutic doses of acetaminophen is known to induce hepatotoxicity and to be associated with high mortality [13-16]. It is also known that caregivers can be reluctant to accept the fact that they made a mistake contributing to child's illness. In our case, the history of consumption reported by the mother has not changed during extended medical and judicial investigations. The statements of the family were verified by a thorough police investigation, including interrogations of mother, relatives, pharmacist, dentist and general 
practitioner involved in the care provision. Interpretation of acetaminophen blood concentration at presentation to hospital should be cautious. We agree that this concentration may be higher than expected. However, various studies conducted reported no correlation between the reported ingested doses and the plasma acetaminophen concentrations [17-19]. The last dose of acetaminophen occurred within 24 hours before admission and therefore the concentration measurement. If we assume the hypothesis of a pre-existing vulnerability leading, in the presence of acetaminophen, to a cellular dysfunction by mitochondrial involvement, then the toxicity no longer results solely from metabolism by an accessory pathway, and taking into account the half-life of acetaminophen alone does not explain the kinetics of hepatic injury.

Besides the presence of parenchymal necrosis in the centrilobular zones, it is noteworthy that microvesicular steatosis was present in the periportal areas. Notably, previous investigations have shown that the occurrence of drug-induced microvesicular steatosis was mainly the consequence of a severe impairment of mitochondrial fatty acid $\beta$-oxidation either via a direct inhibition of this metabolic pathway, or secondary to an alteration of the mitochondrial respiratory chain activity $[20,21]$. Acetaminophen, via the generation of N-acetyl-pbenzoquinoneimine (NAPQI), can induce severe and irreversible mitochondrial dysfunction, thus leading to profound ATP depletion and liver necrosis [22, 23]. Hence, acetaminopheninduced mitochondrial dysfunction is able to induce not only centrilobular necrosis but also microvesicular steatosis [24]. However, acetaminophen has been given to the young patient at therapeutic doses, which might have been unable to induce severe mitochondrial dysfunction. In keeping with this assumption, a recent experimental study in mice showed that low dose acetaminophen induced reversible mitochondrial dysfunction in liver associated to steatosis but without the occurrence of necrosis [25]. 
Hence, alternatively, acetaminophen-induced necrosis and microvesicular steatosis might have been favored in this case by pre-existing mitochondrial dysfunction, as reported for other drugs. For instance, several studies reported the occurrence of severe and even fatal hepatotoxicity induced by therapeutic doses of sodium valproate in patients suffering from an underlying genetic mitochondrial diseases such as a deficiency in medium-chain acylcoenzyme A dehydrogenase (MCAD, a mitochondrial $\beta$-oxidation enzyme), or in one of the five mitochondrial respiratory chain complexes [26, 27]. Unfortunately, we were unable to have biological samples usable for DNA extraction in order to perform genetic analysis in the patient, or her mother.

Although hepatic steatosis is not generally considered as a typical pathological feature in patients suffering from acetaminophen hepatoxicity, some cases of mild steatosis (or mild fatty changes) have been previously reported [24, 28-30]. In one of these studies, the authors reported that fatty microvacuoles were invariably found in the surviving liver cells [21]. Notably, microvesicular steatosis has also been reported in different rodent models of acetaminophen hepatotoxicity [25, 31-33]. In one of these articles, microvesicular steatosis was particularly observed in C57BL/6N mice infected with influenza B virus and pretreated with 3-methylcholanthrene, a potent cytochrome P450 inducer [31]. Interestingly, microvesicular steatosis in this murine model was associated with ultrastructural alterations of mitochondria. Because microvesicular steatosis was not observed in acetaminophenintoxicated mice only infected with influenza B virus, or in acetaminophen-intoxicated mice only pretreated with 3-methylcholanthrene, these data clearly indicated that the occurrence of microvesicular steatosis was due to the presence of concomitant predisposing factors [31]. Finally, it is noteworthy that fatty change and "fine fat vacuoles" (thus indicating 
microvesicular steatosis) were observed in a dog model of acetaminophen-induced fulminant hepatic failure [34]. Considering the aforementioned data as well as our case report, we might recommend that pathologists should report any significant microvesicular steatosis associated with necrosis in patients with acetaminophen-induced liver injury. If possible, the search for potential predisposing factors (either genetic or environmental) might also help to understand why some drugs are able to induce severe microvesicular steatosis in a few patients $[21,26]$.

Wider debate about the evaluation of the hepatotoxic risk of acetaminophen and the medical management of slightly supratherapeutic doses has to be continued, with regard to both patients and health professionals. Concerning patients, the lack of public awareness surrounding safe self-medication has been demonstrated, especially in the context of dental pain, which contributes to a significant number of acute medical admissions as a result of accidental acetaminophen overdose [35]. Concerning health professionals, there is a need for training if we consider the caregivers' knowledge about acetaminophen administration in children. According to Mullan et al. [36], approximately a quarter of them did not know the maximum daily dose, just under half did not know how many days this dose could be safely given, and over one-third did not know that liver toxicity could result from overdose.

\section{Conclusion}

We report an observation of a fatal acute liver failure in a 9-year-old child after allegedly repeated administration of therapeutic doses at 4-hour intervals. Clinical and biological information strongly suggest that acetaminophen exposure is the cause of the ALF. One hypothesis is that this ALF results from an overdose. However no evidence came during the judicial investigation to support this hypothesis. The observation of a microvesicular steatosis 
in the periportal areas, offers another hypothesis, that of increased vulnerability via preexisting mitochondrial dysfunction. In this hypothesis, the scheme of administration consisting in reducing the recommended interval between two doses could have played a role. As the liver status of patients is mostly unknown, the frequency of administration (every six hours) must be respected and the use of pharmaceutical forms allowing to adjust the dose as closely as possible to the child's weight should be promoted [37].

\section{Declaration of Interest statement}

There are no interest statement to declare.

\section{Acknowledgments}

We wish to thank Professor Bruno Megarbane for enriching discussions and interesting comments. 


\section{References}

1. Bunchorntavakul C, Reddy K. Acetaminophen (APAP or N-acetyl-p-aminophenol) and acute liver failure. Clin Liver Dis 2018; 22: 325-334.

2. Lee WM. Acetaminophen (APAP) hepatotoxicity - Isn't it time for APAP to go away? J Hepatol 2017; 67: 1324-13331.

3. Alonso E, Sokol R, Hart J, Tyson W, Narkewicz M, Whittington P. Fulminant hepatitis associated with centrilobular hepatic necrosis in young children, J Pediatr 1995; 127: 888894.

4. Heubi J, Barbacci M, Zimmerman H. Therapeutic misadventures with acetaminophen: Hepatoxicity after multiple doses in children. J Pediatr 1998; 132: 22-27.

5. Watkins PB, Kaplowitz N, Slattery JT, Colonese CR, Colucci SV, Stewart PW, Harris SC. Aminotransferase elevations in healthy adults receiving 4 grams of acetaminophen daily: a randomized controlled trial. JAMA 2006; 296:87-93.

6. Winnike JH, Li Z, Wright FA, Macdonald JM, O'Connell TM, Watkins PB. Use of pharmaco-metabonomics for early prediction of acetaminophen-induced hepatotoxicity in humans. Clin Pharmacol Ther 2010; 88:45-51.

7. Kozer E, Greenberg R, Zimmerman DR, Berkovitch M. Repeated supratherapeutic doses of paracetamol in children - a literature review and suggested clinical approach. Acta Paediatr 2006; 95: 1165-1171.

8. Heard K, Bui A, Mlynarchek SL, Green JL, Bond GR, RF Clark, Kozer E, Koff RS, Dart RC. Toxicity from repeated doses of acetaminophen in children: assessment of causality and dose in reported cases. Am J Thera 2014; 21: 174-183. 
9. Caparrotta, T, Antoine D, Dear J. Are some people at increased risk of paracetamolinduced liver injury? A critical review of the literature. Eur J Clin Pharmacol 2018; 74:147160.

10. Nahata M, Powell D, Durrell D, Miller M. Acetaminophen accumulation in pediatric patients after repeated therapeutic doses. Eur J Clin Pharamcol 1984; 27: 57-59.

11. Penna A, Buchanan N. Paracetamol poisoning in children and hepatotoxicity. Br J Clin Pharmacol 1991; 32: 143-149.

12. Anundi I, Lateenmaki T, Rundrgren M, Moldeus $\mathrm{P}$, Lindros $\mathrm{K}$. Zonation of acetaminophen metabolism and cytochrome P450 2E1-mediated toxicity studied in isolated periportal and perivenous hepatocytes. Biochem Pharmacol 1993; 45: 1251-1259.

13. Heubi JE, Barbacci MB, Zimmerman HJ. Therapeutic misadventures with acetaminophen: hepatoxicity after multiple doses in children. J Pediatr 1998; 132: 22- 27.

14. Rivera-Penera T, Gugig R, Davis J, McDiarmid S, Vargas J, Rosenthal P, et al. Outcome of acetaminophen overdose in pediatric patients and factors contributing to hepatotoxicity. $\mathbf{J}$ Pediatr 1997; 130: 300-304.

15. Heubi JE, Bien JP. Acetaminophen use in children: more is not better. J Pediatr 1997; 130: 175.

16. Sztajnkrycer MJ, Bond GR. Chronic acetaminophen overdosing in children: risk assessment and management. Curr Opin Pediatr 2001; 13: 177-182.

17. Gee P, Ardagh M. Paediatric exploratory ingestions of paracetamol. N Z Med J 1998; 111 : 186-188.

18. Ambre J, Alexander M. Liver toxicity after acetaminophen ingestion: inadequacy of the dose estimate as an index of risk. JAMA 1977; 238: 500-501.

19. Read RB, Tredger JM, Williams R. Analysis of factors responsible for continuing mortality after paracetamol overdose. Hum Toxicol 1986; 5: 201-206. 
20. Begriche K, Massart J, Robin MA, Borgne-Sanchez A, Fromenty B. Drug-induced toxicity on mitochondria and lipid metabolism: mechanistic diversity and deleterious consequences for the liver. J Hepatol 2011; 54: 773-794.

21. Fromenty B, Pessayre D. Inhibition of mitochondrial beta-oxidation as a mechanism of hepatotoxicity. Pharmacol Ther 1995; 67: 101-154.

22. Moles A, Torres S, Baulies A, Garcia-Ruiz C, Fernandez-Checa JC. Mitochondriallysosomal axis in acetaminophen hepatotoxicity. Front Pharmacol 2018; 9: 453.

23. Xie Y, McGill MR, Dorko K, Kumer SC, Schmitt TM, Forster J, Jaeschke H. Mechanisms of acetaminophen-induced cell death in primary human hepatocytes. Toxicol Appl Pharmacol 2014; 279: 266-274.

24. Massart J, Begriche K, Buron N, Porceddu M, Borgne-Sanchez A, Fromenty B. Druginduced inhibition of mitochondrial fatty acid oxidation and steatosis. Curr Pathobiol Rep 2013; 1: 147-157.

25. Hu J, Ramshesh VK, McGill MR, Jaeschke H, Lemasters JJ. Low dose acetaminophen induces reversible mitochondrial dysfunction associated with transient c-Jun $\mathrm{N}$-terminal kinase activation in mouse liver. Toxicol Sci 2016; 150: 204-215.

26. Labbe G, Pessayre D, Fromenty B. Drug-induced liver injury through mitochondrial dysfunction: mechanisms and detection during preclinical safety studies. Fundam Clin Pharmacol 2008; 22: 335-353.

27. Krähenbühl S, Brandner S, Kleinle S, Liechti S, Straumann D. Mitochondrial diseases represent a risk factor for valproate-induced fulminant liver failure. Liver 2000; 20: 346-348.

28. Portmann B, Talbot IC, Day DW, Davidson AR, Murray-Lyon IM, Williams R. Histopathological changes in the liver following a paracetamol overdose: correlation with clinical and biochemical parameters. J Pathol 1975; 117(3): 169-181. 
29. Lubel JS, Angus PW, Gow PJ. Accidental paracetamol poisoning. Med J Aust 2007; 186(7): 371-372.

30. Ramachandran R, Kakar S. Histological patterns in drug-induced liver disease. J Clin Pathol 2009; 62(6): 481-492.

31. MacDonald MG, McGrath PP, McMartin DN, Washington GC, Hudak G. Potentiation of the toxic effects of acetaminophen in mice by concurrent infection with influenza B virus: a possible mechanism for human Reye's syndrome? Pediatr Res 1984; 18(2): 181-187.

32. Song Z, McClain CJ, Chen T. S-Adenosylmethionine protects against acetaminopheninduced hepatotoxicity in mice. Pharmacology 2004; 71(4): 199-208.

33. Belardinelli MC, Pereira F, Baldo G, Vicente Tavares AM, Kieling CO, da Silveira TR, Meurer L, Soares Duarte ME, Giugliani R, Matte U. Adult derived mononuclear bone marrow cells improve survival in a model of acetaminophen-induced acute liver failure in rats. Toxicology 2008; 247(1): 1-5.

34. Gazzard BG, Hughes RD, Mellon PJ, Portmann B, Williams R. A dog model of fulminant hepatic failure produced by paracetamol administration. Br J Exp Pathol 1975; 56(5): 408411.

35. O'Sullivan L, Ahmed N, Sidebottom A. Dental pain management-a cause of significant morbidity due to paracetamol overdose. British dental journal 2018; 224: 623-630.

36. Mullan J, Burns,P, Sargeant D. Caregivers' knowledge about children's paracetamol. Journal of Pharmacy Practice and Research, 2018; 48: 454-458.

37. Bilenko N, Tessler H, Okbe R, Press J, Gorodischer R. Determinants of antipyretic misuse in children up to 5 years of age: a cross-sectional study. Clin Ther 2006; 28: 783-793. 


\section{Figure legends}

Figure 1. Histological features in liver biopsy A: Hepatocytic necrosis around central vein (CV) and steatosis in periportal hepatocytes (PT) (Sirius red stain, X 100) B: Microvesicular steatosis in upper part and necrosis in lower part (HES stain, X 400)
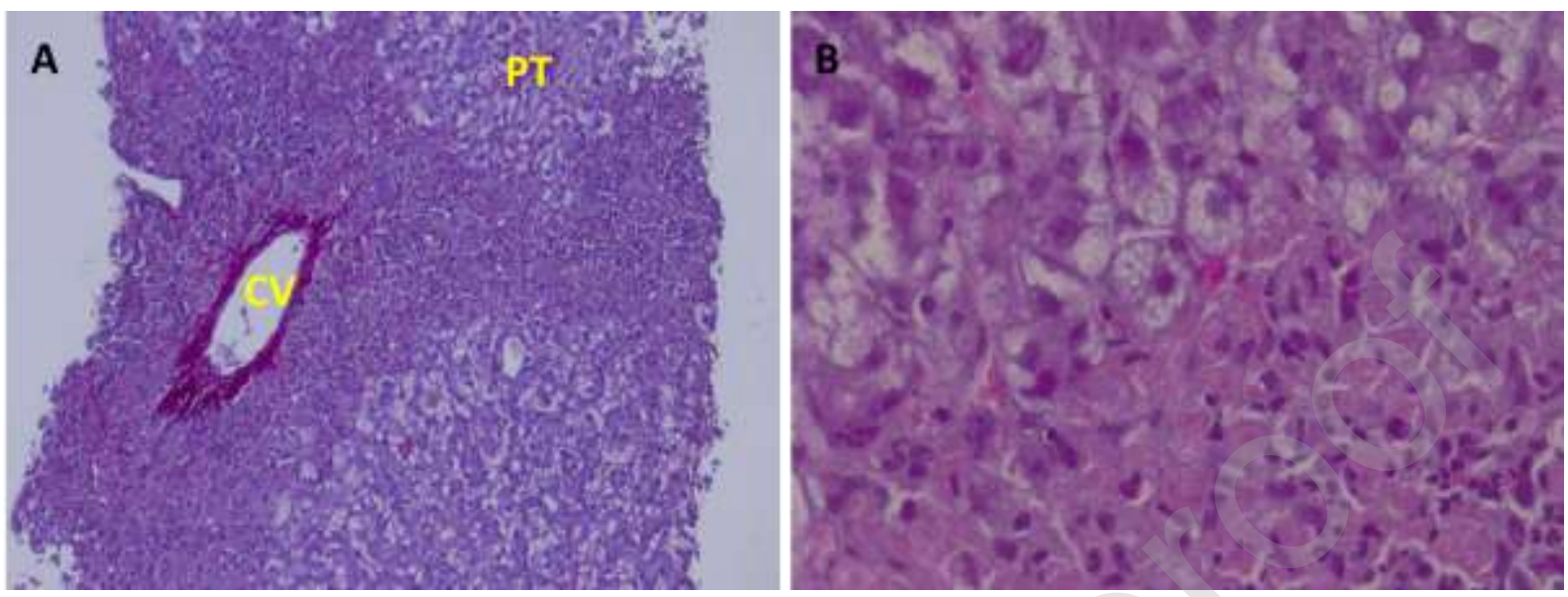

Figure 2. Time frame of events documented by story according to police investigation

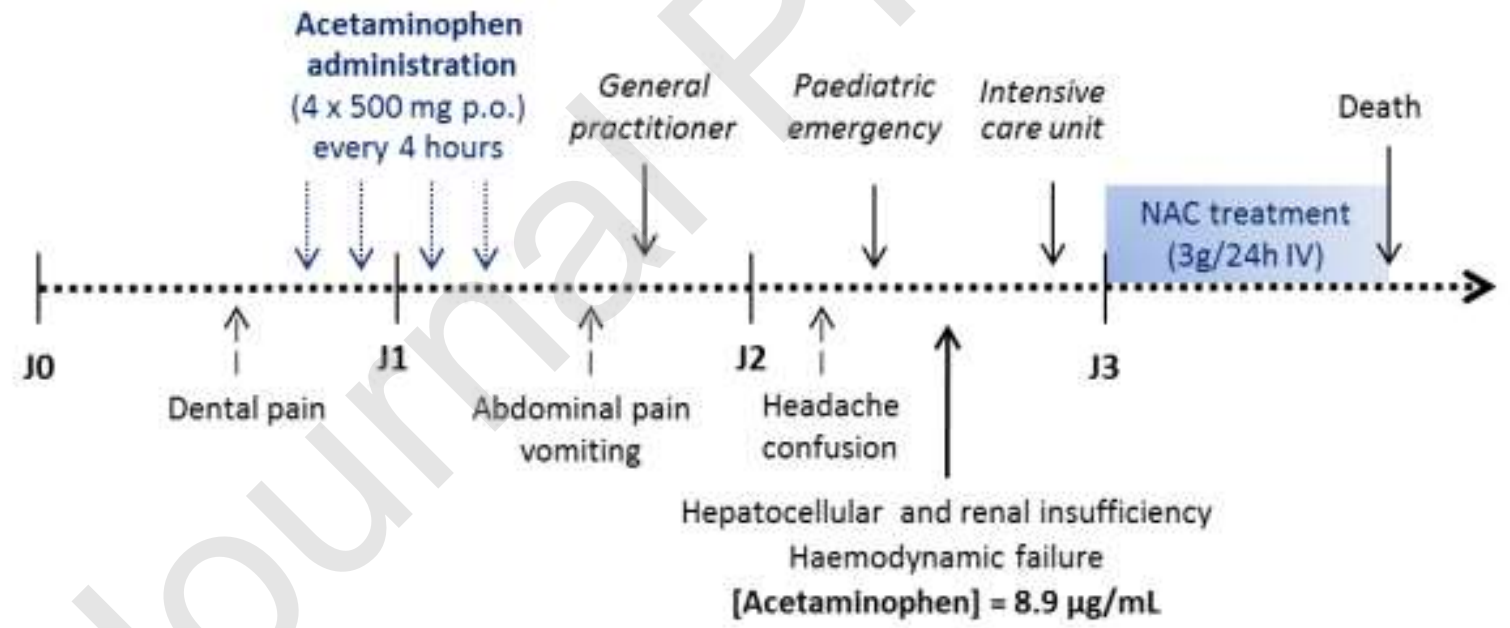

